International Journal of Engineering \& Technology, 7 [2.29] [2018] 737-741
International Journal of Engineering \& Technology
SPC
Website: www.sciencepubco.com/index.php/IJET
Research paper

\title{
The Significance of Main Constructs of Theory of Planned Behavior in Recent Information Security Policy Compliance Behavior Study: A Comparison among Top Three Behavioral Theories
}

\author{
Akhyari Nasir ${ }^{1 *}$, Ruzaini Abdullah Arshah ${ }^{2}$, Mohd Rashid Ab Hamid ${ }^{3}$ \\ ${ }^{I}$ Faculty Of Computer, Media And Technology Management, TATI University College, Teluk Kalong, \\ 24000 Kemaman, Terengganu, Malaysia \\ ${ }^{2}$ Faculty Of Computer Systems \& Software Engineering, Universiti Malaysia Pahang, Lebuhraya Tun Razak, \\ 26300 Kuantan, Pahang, Malaysia \\ ${ }^{3}$ Faculty Of Industrial Sciences \& Technology, Universiti Malaysia Pahang, Lebuhraya Tun Razak, \\ 26300 Kuantan, Pahang, Malaysia \\ *Corresponding Author E-Mail: Akhyari@Tatiuc.Edu.My
}

\begin{abstract}
For a decade since year of 2000 until 2010, Theory of Planned Behavior [TPB] and its main construct of Attitude, Normative belief and Self-efficacy have been considered as a significant theory and factors in the area ISP compliance behaviour study. However, there are still some questions exist particularly on to what extent this theory is significant in recent studies compared to other competing theories. This paper presents a comparison on main constructs of top three behavioral theories in predicting and explaining the recent ISP compliance studies. The studies on ISP compliance published from 2010 until 2016 will be used to analyse the significance of this TPB compared to General Deterrence Theory [GDT] and Protection Motivation Theory [PMT]. Criteria of comparisons are based on the significance of main constructs towards dependent variable and the comprehensiveness of a theory's main constructs usage in a research model from the selected studies. The results have confirmed that TPB is still relevant as the most significant in the area of ISP compliance study and its main constructs are the strongest predictors of dependent variables in most of ISP compliance models compare to GDT and PMT. This paper provides a clear status on the significance of TPB and its main constructs of Attitude, Normative belief and Self-efficacy in predicting and explaining ISP compliance behavior in recent studies. It could be used by academicians as references for statistical evidences on the comparison of the top behavioral theories.
\end{abstract}

Keywords: Behavioral Theory; Theory of Planned Behavior; Information Security Policy Compliance; Security Behavior

\section{Introduction}

In ISP compliance and incompliance literature, there are many behavioral theories have been adopted and adapted to explain and predict this issue. It is because this area of study is surrounding the behavior of human in dealing with information assets that documented in company ISP. At the same time, adopting behavioral theories in research models will provide more relevant findings as well as more powerful explanations and understanding [Ifinedo, 2012; Mishra and Dhillon, 2005] on particular behaviors in ISP compliance context. Among many theories, Theory of Planned Behavior [TPB], General Deterrence Theory, Protection Motivation Theory [PMT] are the most and common used in this area and it was widely acknowledged in reviews by Lebek, Uffen, Neumann, Hohler, \& H. Breitner [2014] and Sommestad, Hallberg, Lundholm, \& Bengtsson [2014].

Interestingly, among these three theories, TPB was found to be the most significant one. According to Lebek et al. [2014], this theory with its main construct, which are Attitude [ATT], Normative Belief [NB] and Self-Efficacy [SE] are the most significant behavioral factor in predicting and explaining information security be- havior. Other reviews also have acknowledged the strength and significance of this theory and its main constructs in this area such by Sommestad \& Hallberg [2013] and Sommestad, Hallberg, et al. [2014]. However, there are two questions are still exist in confirming this fact. The first one is, to what extent TPB was significant in recent studies compare to other competing theories because there are many more recent studies have been conducted and published in this area and all these studies are not included in the previous review by Lebek et al. [2014]. There is no detail comparison in terms of main constructs of each competing theories with main construct of TPB towards predicting and explaining ISP compliance behavior. Another question is, to what extent all these main constructs for each theory are applicable in a research model in order to confirm the comprehensiveness of each theory's main constructs in predicting and explaining ISP compliance behavior. This paper is addressing these two questions by comparing three top behaviour theories in terms of their main constructs to analyse their significance in ISP compliance studies. The next section will discuss the method used in this review followed by the section of results and discussion that will show and discuss all the finding in answering the two questions. This paper conclude the review by 
giving the summary of comparison among these three theories in terms of certain criteria that will justify the strength and ability of main constructs of each theories in predicting and explaining recent ISP compliance behaviour of employees in organizational settings.

\section{Methodology}

This review involved the searching and analyzing of theories of TPB, GDT and PMT used in the recent ISP compliance studies. Relevant literature were identified through a carefully structured literature search as the quality of a literature review strongly depends on the search process [4].

The online databases of ScienceDirect, IEEEXplore, SpringerLink, ACM, Wiley, Researchgate, InformsOnline, Emerald, and AISeL are used to find the latest studies on ISP compliance and violation in current literature. The search criterion were based on keywords or combinations of specific terms such as "Information Security Policy Compliance", "Information Security Policy Violation", "Information Security Compliance Behavior", "Information Security Compliance Behavior", "Information Security Violation Behavior", "Security Compliance Behavior", "Employee ISP Compliance" and "Security Violation Behavior". Another inclusion criteria included are:

The studies must directly investigate employees' compliance or violation behavior towards ISP in the organization

The studies must use TPB, GDT and/or PMT in the research model.

The studies must have empirical results and findings of the relationship between constructs and dependent variable under reviewed

The studies must be published in the period of 2010 until 2016

The studies must be written in English

The selected articles are thoroughly read and analyzed to identify the criteria of comparison used in this review, which are:

The significant relationship of a theory's main constructs towards dependent variable, and

The comprehensiveness of a theory's main constructs usage in a research model

\section{Result and Discussion}

The searching process based on particular criteria as well as careful reading and analysis has found 38 articles that specifically use TPB, GDT and PMT in the studies. In general, it was found that TPB is the most popular behavioral theory used in recent ISP compliance studies. From 38 studies, 15 studies have used TPB, 13 used GDT and 10 studies have used PMT.

Table 1, 2 and 3 shows the statistical significance of each theory's common main construct towards Dependent Variable [DV] used in a research model in ISP compliance/incompliance behavior study. The DV used for this review are Intention to Comply [INT], Actual Compliance $[\mathrm{ACT}]$ and Attitude towards Compliance [ATT]. These three constructs are the most common DVs used in ISP compliance literature [1,2]. Interestingly, these three variables are also among the variables contained in TPB [5].

Tables 1 clearly show that the main constructs of TPB, which are ATT, NB and SE have the most number of significant relationship towards DV compared to main constructs of GDT and PMT as shown in Table 2 and Table 3 respectively. Specifically, according to Table 1, construct of ATT was $100 \%$ significant in all 15 studies. This construct is the most dominant factor and some studies such as in Bulgurcu, Cavusoglu, \& Benbasat [2011] and Kajtazi \& Bulgurcu [2013] have utilized this factor as DV in their studies. Another two constructs of NB and SE also are the strong predictors of ISP compliance behavior. All studies have indicated a significant relationship of these two constructs towards DV and only one study which is by Kim et al. [2014] and Borena and Bélanger [2013] has respectively found that SE and NB was not significant. However, as for NB, although this construct was found as not significant towards INT in Borena \& Bélanger [2013], it was actually has significant relationship towards ATT in the study. Since ATT is also one of the common DV in ISP compliance studies, therefore construct of NB is actually has significant relationship towards another DV in this study. All these scenario have confirmed that almost all studies that used the main constructs of TPB have found significant relationship towards DV and this is consistent with the prior review by Lebek et al. [2014], which found that all these three factors are significant and strong predictors towards DVs used ISP compliance behavior studies.

At the same time, Table 1 also depicted that most of the time, the studies that adopted this theory have always using all the main constructs in the research model of a study. This somehow suggested the ability and the comprehensiveness of this theory's main constructs in predicting and explaining the phenomena of ISP compliance behaviour. Although there are few studies have not used all the main constructs, it is not an issue. Specifically, in the studies of Bulgurcu et al. [2011] and Kajtazi \& Bulgurcu [2013], the authors used this theory just to utilized the construct of ATT and INT to be as DV in their study rather than to examine the significance and comprehensiveness of the all main constructs in explaining ISP compliance behaviour. Thus, it is confirmed that each of these TPB constructs is significant and has its own role and strength in predicting and explaining ISP compliance behavior. In comparison with two other popular theories which are GDT and PMT, findings showed that the main constructs of these two theories were not as convincing as TPB in predicting and explaining ISP compliance/incompliance behavior as indicated in Table 2 and Table 3. As for GDT, the table clearly shows that its main constructs which are Perceived Certainty of Sanctions [PCS], Perceived Severity of Sanctions [PSS] and Informal Sanctions [IS] are not as strong as TPB's main constructs in terms of number of significant relationship towards DV. Most of GDT's main constructs could not provide a conclusive relationship towards DV and the findings are not consistent from one study to another. According to Table 2, unlike TPB, there is no $100 \%$ significant results of any of these main constructs toward DV and most of the time they produced mixed findings among these studies. For example, PCS have found significant in Li, Zhang, et al. [2010] and M. Siponen et al. [2010] but not significant in the studies of Cheng et al. [2013], Hu et al. [2011] and Son [2011]. As for PSS, this construct was found significant in Sal Aurigemma \& Mattson [2014], Chen, Ramamurthy, \& Wen [2013] and Cheng et al. [2013] but not in Hu et al. [2011], Li, Sarathy, \& Zhang [2010a] and Son [2011]. The same scenario also happened to construct of IS, which was found significant in Guo and Yuan [2012] and M. Siponen et al. [2010] but not in Li, Zhang, et al. [2010] and M. Siponen and Vance [2010].

As for main constructs of PMT, although Table shown stronger results compared to GDT in terms of significant relationship, it still has some issues especially in terms of the usage and applicability of its main constructs in a research model. Table 2 shows many cases of NA [not applicable] of a construct of this theory in a research model. This means that most of the studies that used and utilized PMT have not applied all the main constructs in the study. Only studies of Ifinedo [2012] and Vance, Siponen, \& Pahnila [2012] have used all the PMT main constructs in as a single factor [without combination] towards a DV in their models. Some studies have combined certain constructs and this somehow suggested that a single construct of these main constructs is not strong enough in providing a significant relationship towards a DV in a study. It is consistent with study by Sommestad, Karlzén, et al. [2014] that proved the addition of PMT constructs into TPB framework did not provide much different in explaining ISP compliance behavior.

The same scenario also happened to GDT. Most of the studies that adopted GDT have not used the entire main constructs in a research model. Like PMT, some studies have combined particular constructs in relationship with DV in a study. Unlike TPB, GDT constructs were not consistently used in most of the ISP compliance behaviour models. At some extent, there is no consistency in 
terms of usage of GDT's main constructs from one study to another. For example, according to Table 2, most of the studies used constructs of PCS and PSS as Independent Variables [IV] but other studies have combined these two constructs to represent IV of Formal Sanctions in their research models such as in Guo, Yuan, Archer, \& Connelly [2011], Siponen \& Vance [2010] and Vance [2012]. Moreover, some studies used one of these two constructs
[16] and interestingly some studies did not used these two constructs [18] at all even though these two constructs are the most common constructs for this theory. Nonetheless, all these arguments have led to a conclusion that the main constructs of PMT and GDT are not convincing enough as TPB in explaining ISP compliance/incompliance behavior of employees in the organization.

Table 1: Statistical Significance of TPB's Main Constructs in Recent ISP Compliance Behavior Studies

\begin{tabular}{|c|c|c|c|c|}
\hline \multirow[t]{2}{*}{ No. } & \multirow[t]{2}{*}{ Authors } & \multicolumn{3}{|c|}{ Significance of results of TPB's constructs towards dependent variable in a Research Model } \\
\hline & & Attitude [ $\beta]$ & Self-Efficacy $[\beta]$ & Normative Belief $[\beta]$ \\
\hline 1. & Hu et al. [2012b] & $0.197 * * *$ & $0.360 * * *$ & $0.366 * * *$ \\
\hline 2. & Kim et al. [2014] & $0.303 * * *$ & $0.07 \mathrm{NS}$ & $0.25 * * *$ \\
\hline 4. & Kranz and Haeussinger [2014] & $0.242 * *$ & $0.84 * *$ & $0.216 * *$ \\
\hline 5. & Al-Omari et al., [2013] & $0.12 *$ & $0.25^{*}$ & $0.14 *$ \\
\hline 6. & $\begin{array}{l}\begin{array}{l}\text { Sommestad, Karlzén, et al. } \\
{[2014]}\end{array} \\
\end{array}$ & $0.35^{* *}$ & $0.21 * *$ & $0.22 * *$ \\
\hline 7. & Ifinedo [2014a] & $0.63 * * *$ & $0.18^{*}$ & $0.15^{*}$ \\
\hline 8. & Ifinedo [2012] & $0.48 * * *$ & $0.17 * *$ & $0.19 * *$ \\
\hline 9. & Cox [2012] & $0.12 *$ & $0.15^{*}$ & $0.73 *$ \\
\hline 10. & Bulgurcu et al. [2011] & As dependent Variable & NA & NA \\
\hline 11. & $\begin{array}{l}\text { Sal Aurigemma and Mattson } \\
\text { [2014] }\end{array}$ & $0.584 * *$ & NA & NA \\
\hline 12. & Borena and Bélanger [2013] & $0.447 * * *$ & $0.316^{* * *}$ & $\begin{array}{ll}- & 0.352 * * *[\mathrm{ATT}] \\
\text { - } & \mathrm{NS}[\mathrm{INT}]\end{array}$ \\
\hline 13. & Al-Omari et al. [2012] & $0.206^{*}$ & $0.119 *$ & $0.233 *$ \\
\hline 14. & M Kajtazi and Bulgurcu [2013] & As dependent variable & NA & NA \\
\hline 15. & $\begin{array}{l}\text { Salvatore Aurigemma } \& \\
\text { Mattson [2015] }\end{array}$ & NA & $0.390 * *$ & NA \\
\hline \multicolumn{5}{|c|}{$\begin{array}{l}* \mathrm{p}<0.05, * * \mathrm{p}<0.01, * * * \mathrm{p}<0.001 \\
\mathrm{NS}-\text { Not Significant } \\
\mathrm{NA}-\text { Not used in the study }\end{array}$} \\
\hline
\end{tabular}

Table 0: Statistical Significance of GDT's Main Constructs in Recent ISP Compliance Behavior Studies

\begin{tabular}{|c|c|c|c|c|}
\hline \multirow[t]{2}{*}{ No. } & \multirow[t]{2}{*}{ Study } & \multicolumn{3}{|c|}{ Significance of results of GDT's constructs towards dependent variable in a Research Model } \\
\hline & & $\begin{array}{l}\text { Perceived Certainty } \\
\text { Sanctions }[\beta]\end{array}$ & Perceived Severity of Sanctions $[\beta]$ & Informal Sanctions $[\beta]$ \\
\hline 1. & Q. Hu et al. [2011] & $-0.082 \mathrm{NS}$ & $-0.087 \mathrm{NS}$ & NA \\
\hline 2. & Son, Jai-Yeol [2011] & $0.05 \mathrm{NS}$ & $0.06 \mathrm{NS}$ & NA \\
\hline 3. & [Li, Zhang, et al. [2010] & $0.24 * *$ & $-0.12 \mathrm{NS}$ & $-0.09 \mathrm{NS}$ \\
\hline 4. & Cheng et al. [2013] & $0.27 \mathrm{NS}$ & $-0.311 * * *$ & NA \\
\hline 5. & Hovav and D'Arcy, [2012] & $\begin{array}{ll}-0.20 * * \text { for Korean } \\
\text { Sample } \\
-0.06 \text { NS for US Sample } \\
\end{array}$ & $\begin{array}{ll}\text { - } & -0.14^{* *} \text { for US Sample } \\
\text { - } & -0.04 \text { NS for Korean Sample }\end{array}$ & NA \\
\hline 6. & M. Siponen et al. [2010] & \multicolumn{3}{|l|}{$\begin{array}{l}0.09 * * * \\
\text { [combined] }\end{array}$} \\
\hline 7. & $\begin{array}{l}\text { M. Siponen and A. Vance } \\
{[2010]}\end{array}$ & \multicolumn{2}{|l|}{$\begin{array}{l}0.4 \mathrm{NS} \\
\text { [combined] }\end{array}$} & $-0.07 \mathrm{NS}$ \\
\hline 8. & Guo and Yuan [2012] & NA & $\mathrm{NA}$ & $-0.41 * * *$ \\
\hline 9. & $\begin{array}{l}\text { Sal Aurigemma and Mattson } \\
\text { [2014] }\end{array}$ & NS & $0.282 *$ & NA \\
\hline 10. & Y. Chen et al. [2013] & NA & $0.29 * *$ & NA \\
\hline 11. & Vance [2012] & \multicolumn{2}{|l|}{$\begin{array}{l}-0.02 \mathrm{NS} \\
\text { [combined] }\end{array}$} & $-0.10^{*}$ \\
\hline 12. & Guo et al. [2011] & \multicolumn{2}{|l|}{$\begin{array}{l}-0.053 \mathrm{NS} \\
\text { [combined] }\end{array}$} & $0.225 * * *$ \\
\hline 13. & Li, Sarathy, et al. [2010] & $0.13 *$ & $0.06 \mathrm{NS}$ & NA \\
\hline \multicolumn{5}{|c|}{$\begin{array}{l}* \mathrm{p}<0.05, * * \mathrm{p}<0.01, * * * \mathrm{p}<0.001 \\
\mathrm{NS}-\text { Not Significant } \\
\text { NA - Not used in the study } \\
\text { [combined] - the result is a combination of effect of particular main contructs towards dependent variable }\end{array}$} \\
\hline
\end{tabular}

Table 3: Statistical Significance of PMT's Main Constructs in Recent ISP Compliance Behavior Studies

\begin{tabular}{|c|c|c|c|c|c|c|}
\hline \multirow[t]{2}{*}{ No. } & \multirow[t]{2}{*}{ Study } & \multicolumn{5}{|c|}{ Significance of results of PMT's constructs towards dependent variable in a Research Model } \\
\hline & & $\begin{array}{l}\text { Perceived } \\
\text { Vulnerability [ } \beta]\end{array}$ & $\begin{array}{l}\text { Perceived Severity } \\
{[\beta]}\end{array}$ & $\begin{array}{l}\text { Respond } \\
\text { Efficacy }[\beta]\end{array}$ & Self-Efficacy $[\beta]$ & Respond Cost $[\beta]$ \\
\hline 1. & M. Siponen et al. 2014 & $0.062 *$ & $0.069 *$ & $0.13 \mathrm{NS}$ & $0.87 * *$ & NA \\
\hline 2. & Ifinedo [2012] & $0.20 * *$ & $-0.20 *$ & $0.27 * *$ & $0.17 * *$ & $-0.12 \mathrm{NS}$ \\
\hline 3. & $\begin{array}{l}\text { T. Sommestad et al. } \\
\text { [2014] }\end{array}$ & \multicolumn{2}{|l|}{$\begin{array}{l}0.04 \text { significant* } \\
\text { [combined] }\end{array}$} & \multicolumn{3}{|l|}{$0.01 \mathrm{NS}$} \\
\hline
\end{tabular}




\begin{tabular}{|c|c|c|c|c|c|c|}
\hline 4. & A. Vance et al. [2012] & $0.10 \mathrm{NS}$ & $0.27 * * *$ & $-0.21 * * *$ & $0.34 * * *$ & $-0.18^{*}$ \\
\hline 5. & $\begin{array}{l}\text { Johnston and Warkentin } \\
\text { [2010a] }\end{array}$ & NA & NA & $0.213^{*}$ & $0.187^{*}$ & $\mathrm{NA}$ \\
\hline 6. & Cox [2012] & $0.9^{*}$ & $0.39 \mathrm{NS}$ & NA & NA & NA \\
\hline 8. & Kim et al., [2014] & NA & NA & $0.266 * * *$ & NA & NA \\
\hline 9. & Lee, Lee, \& Kim [2016] & $0.48 * * *$ & NA & NA & NA & $\mathrm{NA}$ \\
\hline 10. & Hovav \& Putri [2016] & \multicolumn{2}{|l|}{$\begin{array}{l}0.168^{*} \\
\text { [combined] }\end{array}$} & $0.330 * * *$ & $0.091 \mathrm{NS}$ & $\mathrm{NA}$ \\
\hline \multicolumn{7}{|c|}{$\begin{array}{l}* \mathrm{p}<0.05, * * \mathrm{p}<0.01, * * * \mathrm{p}<0.001 \\
\mathrm{NS}-\text { Not Significant } \\
\mathrm{NA}-\text { Not used in the study } \\
\text { [combined] - the result is a combination of effect of particular main contructs }\end{array}$} \\
\hline
\end{tabular}

Table 4: Summary of Comparison Among TPB, GDT and PMT

\begin{tabular}{|c|c|c|c|c|c|}
\hline Theory & $\begin{array}{c}\text { Main } \\
\text { Constructs }\end{array}$ & $\begin{array}{l}\text { No. of } \\
\text { occurrences in } \\
\text { recent studies }\end{array}$ & $\begin{array}{l}\text { No. of studies that have } \\
\text { significant relationship } \\
\text { towards DV }\end{array}$ & $\begin{array}{l}\text { Percentage of number of } \\
\text { significant relationship of main } \\
\text { constructs towards a DV }\end{array}$ & $\begin{array}{l}\text { No. of studies that used } \\
\text { all the main constructs } \\
\text { without combination }\end{array}$ \\
\hline \multirow{3}{*}{ TPB } & ATT & 12 & 12 & $100 \%$ & \multirow{3}{*}{12} \\
\hline & SE & 12 & 11 & $91.7 \%$ & \\
\hline & NB & 12 & 11 & $91.7 \%$ & \\
\hline \multirow{3}{*}{ GDT } & PCS & 12 & 4 & $33.3 \%$ & \multirow{3}{*}{1} \\
\hline & PSS & 13 & 4 & $30.8 \%$ & \\
\hline & IS & 5 & 3 & $60 \%$ & \\
\hline \multirow{4}{*}{ PMT } & PS & 7 & 6 & $85.7 \%$ & \multirow{4}{*}{2} \\
\hline & RV & 8 & 5 & $62.5 \%$ & \\
\hline & SE & 7 & 5 & $71.4 \%$ & \\
\hline & $\mathrm{RC}$ & 3 & 1 & $33.3 \%$ & \\
\hline
\end{tabular}

Table 4 shows a summary of comparison among these leading theories in recent studies. The comparison criteria were selected to focus on the research questions of this review. The table clearly shows that the main constructs of TPB consistently have the most number of significant relationships towards a DV in a research model. Although two constructs of PV and PS from PMT also have many number of significant relationship towards DV in particular research models, however these two constructs are not strong enough to be as a single construct compared to the main constructs of TPB. As discussed before, there are some studies have combined these two constructs together to represent a construct of Threat Appraisal. On the other hand, main constructs of TPB are representing distinctive elements of concept and each of them is significant in predicting and explaining ISP compliance behaviour. Furthermore, as shown in Table 4, TPB has the most number of studies that used all of its main constructs, which is 12 compared to PMT and GDT that recorded only 2 and 1 respectively. All in all, it is clearly shows that all the comparison criteria are suggesting that TPB is the most dominant theory and has the most significant main constructs in predicting and explaining employees' ISP compliance behavior. These facts are consistent with review of previous ISP compliance studies.

\section{Conclusion and limitation}

This paper provides a clear status on the significance of TPB and its main constructs of Attitude, Normative belief and Self-efficacy in predicting and explaining ISP compliance behavior in recent studies. The review found that its main constructs are the strongest predictors compared to main constructs of DGT and PMT. Furthermore, the main constructs of TPB are always consistent in terms of the usage of all its constructs in the research models compared to main constructs of DGT and PMT. These two criteria have provided more convincing findings in terms of comparison among top behavioral theories in this area of study. This review provides a new perspective of comparison based on comprehensiveness of usage of main constructs in a study as additional significant comparison criteria to be highlighted. he findings could be used by academicians as references for statistical evidences on the comparison of the top behavioral theories. Nevertheless, since this review is done using simple comparison in terms of significant relationship and the comprehensiveness of main construct usage in a study, more thorough statistical analysis such as meta-analysis could be done to get deeper and wider findings on the strength and weaknesses of main constructs of these three behavioural theories in predicting and explaining ISP compliance behaviour.

\section{Acknowledgement}

This research is supported by UMP Post Graduate Research Grant Scheme, PGRS170303. The authors fully acknowledged Universiti Malaysia Pahang [UMP] for the approved fund which makes this important research viable and effective

\section{References}

[1] Sommestad T, Hallberg J, Lundholm K, Bengtsson J. Variables influencing information security policy compliance. Inf Manag Comput Secur. 2014;22[1]:42-75

[2] Lebek B, Uffen J, Neumann M, Hohler B, H. Breitner M. Information security awareness and behavior: a theory-based literature review. Manag Res Rev. 2014;37[12]:1049-92.

[3] Sommestad T, Hallberg J. A Review of the Theory of Planned Behaviour in the Context of Information Security Policy Compliance. 2013;257-71.

[4] von Brocke J, Simons A, Niehaves B, Riemer K, Plattfaut R, Cleven A, et al. Reconstructing the Giant: On the Importance of Rigour in Documenting the Literature Search Process. 17th Eur Conf Inf Syst. 2009;2206-2217.

[5] Ajzen I. The Theory of Planned Behavior. Organ Behav Hum Decis Process. 1991;211[50]:179-211.

[6] Bulgurcu B, Cavusoglu H, Benbasat I. Information security policy compliance: the role of fairness, commitment, and cost beliefs. MCIS 2011 Proc. 2011;

[7] Kajtazi M, Bulgurcu B. Information Security Policy Compliance: An Empirical Study on Escalation of Commitment. 19th Am Conf Inf Syst AMCIS 2013 - Hyperconnected World Anything, Anywhere, Anytime. 2013;3:2011-20.

[8] Kim SH, Yang KH, Park S. An integrative behavioral model of information security policy compliance. ScientificWorldJournal. 2014;2014:463870.

[9] Borena B., Bélanger F. Religiosity and information security policy compliance. 19th Am Conf Inf Syst AMCIS 2013 Hyperconnected World Anything, Anywhere, Anytime. 2013;4:2848-55 
[10] 1Li H, Zhang J, Sarathy R. Understanding compliance with internet use policy from the perspective of rational choice theory. Decis Support Syst. 2010;48[4]:635-45.

[11] Siponen M, Pahnila S, Mahmood MA. Compliance with information security policies: An empirical investigation. Computer [Long Beach Calif]. 2010;43[2]:64-71.

[12] $1 \mathrm{Hu} \mathrm{Q}, \mathrm{Xu} \mathrm{Z}$, Dinev T, Ling H. Does deterrence work in reducing information security policy abuse by employees? Commun ACM. 2011;54[6]:54

[13] Son J-Y. Out of fear or desire? Toward a better understanding of employees' motivation to follow IS security policies. Inf Manag. 2011;48[7]:296-302.

[14]Cheng L, Li Y, Li W, Holm E, Zhai Q. Understanding the violation of IS security policy in organizations: An integrated model based on social control and deterrence theory. Comput Secur. 2013;39:447-59.

[15] Aurigemma S, Mattson T. Do it OR ELSE! Exploring the Effectiveness of Deterrence on Employee Compliance with Information Security Policies. Amcis 2014. 2014;1-12.

[16] Chen Y, Ramamurthy KR, Wen K. Organizations ' Information Security Policy Compliance: Stick or Carrot Approach? 2013;29[3]:157-88.

[17] Li H, Sarathy R, Zhang J. Understanding Compliance with Internet Use Policy: An Integrative Model Based on Command- andControl and Self-Regulatory Approaches Understanding Compliance with Internet Use Policy: An Integrative Model Based on Command-and- Control and Self-Regulato. 2010;

[18] Guo KH, Yuan Y. The effects of multilevel sanctions on information security violations: A mediating model. Inf Manag. 2012;49[6]:320-6.

[19] Siponen M, Vance A. Neutralizaiton: New Insights into the Problem of Employee Information Systems Security. MIS Q. 2010;34[3]:487-502.

[20] Ifinedo P. Understanding information systems security policy compliance: An integration of the theory of planned behavior and the protection motivation theory. Comput Secur. 2012;31[1]:83-95.

[21]21. Vance A, Siponen M, Pahnila S. Motivating IS security compliance: Insights from Habit and Protection Motivation Theory. Inf Manag. 2012;49[3-4]:190-8.

[22] Sommestad T, Karlzén H, Hallberg J. The sufficiency of the theory of planned behavior for explaining information security policy compliance. 2014;

[23] Vance A. IS Security Policy Violations : 2012;24[March]:21-41.

[24] Guo KH, Yuan Y, Archer NP, Connelly CE. Understanding Nonmalicious Security Violations in the Workplace: A Composite Behavior Model. J Manag Inf Syst. 2011;28[2]:203-36.

[25] Hu Q, Dinev T, Hart P, Cooke D. Managing Employee Compliance with Information Security Policies: The Critical Role of Top Management and Organizational Culture *. Decis Sci J Innov Educ. 2012;43[4]:615-60.

[26] Bulgurcu B, Cavusoglu H, Benbasat I. Information Security Policy Compliance: An Empirical Study of Rationality-Based Beliefs and Information Security Awareness. Br J Anaesth. 2010;106[2]:199 201.

[27] Kranz JJ, Haeussinger FJ. Why Deterrence is not Enough: The Role of Endogenous Motivations on Employees' Information Security Behavior. nternational Conf Inf Syst. 2014; [October]:1-14.

[28] Al-Omari A, Deokar A, El-Gayar O, Walters J, Aleassa H. Information Security Policy Compliance: An Empirical Study of Ethical Ideology. 2013 46th Hawaii Int Conf Syst Sci. 2013;301827.

[29] Ifinedo P. Information systems security policy compliance: An empirical study of the effects of socialisation, influence, and cognition. Inf Manag. 2014;51[1]:69-79.

[30] Cox J. Information systems user security: A structured model of the knowing-doing gap. Comput Human Behav. 2012;28[5]:1849-58.

[31] Al-Omari A, El-Gayar O, Deokar A. nformation Security Policy Compliance: The Role of Information Security Awareness. In 2012.

[32] Aurigemma S, Mattson T. The Role of Social Status and Controllability on Employee Intent to Follow Organizational Information Security Requirements. In: 2015 48th Hawail International Conference on System Sciences. IEEE; 2015. p. 3527-36.

[33] Hovav A, D’Arcy J. Applying an extended model of deterrence across cultures: An investigation of information systems misuse in the U.S. and South Korea. Inf Manag. 2012;49[2]:99-110.
[34]Johnston AC, Warkentin M. F EAR A PPEALS AND I NFORMATION S ECURITY B EHAVIORS : A N E MPIRICAL S TUDY 1. 2010;34[3]:549-66.

[35]Lee C, Lee CC, Kim S. Understanding information security stress: Focusing on the type of information security compliance activity. 2016;

[36] Hovav A, Putri FF. This is my device! Why should I follow your rules? Employees' compliance with BYOD security policy. Pervasive Mob Comput. 2016;32:35-49. 